\title{
ORGANIZACIÓN DE LAS VIVIENDAS EN UN ENTORNO GEOGRÁFICO RURAL
}

\author{
ORGANIZATION OF DWELLINGS IN A RURAL GEOGRAPHICAL \\ ENVIRONMENT \\ (D) Ángel Alcides Aronés Cisneros ${ }^{*}$ \\ a.arones@pucp.pe \\ ${ }^{1}$ Universidad Nacional San Cristóbal de Huamanga, Ayacucho, Perú
}

*Correspondencia: Ángel Alcides Aronés Cisneros. Email: a.arones@pucp.pe

Recibido: 07.08.2020 | Aprobado: 11.09.2020

\section{RESUMEN}

El objetivo fue analizar la organización de las viviendas en un ámbito geográfico rural, los datos se obtuvieron de entrevistas, apoyada con los sistemas de información geográfica que permitió elaborar mapas temáticos para su interpretación. Evidenciando como resultado que el 44.7\% de las viviendas están ubicadas entre 200 a 400 metros de distancia hacia el río; tres habitaciones, el techo de calamina y los muros con adobe son características comunes. Se concluyó que las viviendas en el ámbito rural están dispersas por condiciones que necesariamente no obedecen las actividades económicas, si no por elementos geográficos, siendo primordial la cercanía a una fuente de agua.

Palabras clave: Viviendas, entorno rural, geografía y organización.

\begin{abstract}
The objective was to analyze the organization of the dwellings in a rural geographical area, the data were obtained from interviews, supported by the geographical information systems that applied thematic maps for their interpretation. Evidenced as a result that $44.7 \%$ of the homes are located between 200 to 400 meters away from the river. Three rooms, the corrugated iron roof and the adobe walls are common features. It was concluded that the dwellings in rural areas are dispersed by conditions that are not necessarily obeyed by economic activities, but by geographical elements, being the proximity to a water source essential.
\end{abstract}

Keywords: Housing, rural environment, geography and organization. 


\section{INTRODUCCIÓN}

Las viviendas de la población rural en los andes del Perú se encuentran dispersas, cuyos servicios básicos son precarios o carentes. En algunos casos una habitación es utilizada como cocina y dormitorio. Estas condiciones crean enfermedades que se relacionan con problemas respiratorios, cutáneos y oculares, de la presión arterial, dolores de cabeza y espalda. Asimismo, se le relaciona con la desnutrición crónica que afecta a niñas, niños y personas adultas mayores (INEI, 2018).

La Organización Mundial de la Salud (2018) estima que más de 4 millones de personas mueren prematuramente todos los años a causa de la exposición al humo en lugares cerrados como resultado de la quema de combustibles sólidos. En las zonas rurales alto andinas el principal combustible para preparar alimentos es la leña y son utilizados diariamente en la preparación de sus alimentos. Estos ambientes para la cocina no están diseñados para evitar la no concentración de la combustión de la leña. Si bien la organización y características de las viviendas están acordes a sus modos de vida de las familias la investigación enfatiza la ubicación de las viviendas en relación a un elemento geográfico y la forma de organización y ocupación habitacional.

El establecimiento de las viviendas y la organización de esta, no garantiza una vida digna por la carencia de servicios y espacios adecuados para la habitabilidad en condiciones justas de las familias (Martínez, 2015).

En el art. 6 de la Constitución Política del Perú señala que "Toda persona tiene derecho a una vivienda digna con acceso a servicios básicos. El Estado promueve programas públicos y privados de urbanización, destugurización y vivienda. Regula la utilización del suelo urbano y rural, con la participación de la comunidad local, de acuerdo a ley"

El Ministerio de Vivienda, Construcción y Saneamiento (2006) indica que “...no hay vida sin agua y no hay vida digna sin vivienda. Agua y vivienda son dos de las necesidades más elementales de los seres humanos y definen la esencia de una vida decente" El reconocimiento del Ministerio sobre la importancia de una vivienda y el agua potable como elementos vitales que definen la esencia de una vida digna de las personas es un avance significativo y entender que las familias sin estos elementos básicos se encuentran en desventaja y con limitada oportunidad de seguir desarrollando y mejorando su calidad de vida.

El entorno geográfico en la organización de las viviendas, es necesario explicar la evolución y el significado de la vivienda desde lo social, económica, urbanística y antropológica (Almeida, C; Mora, J.; Dosreis, F.; 2010). Para Lestel (2001), en tanto la elección de un lugar está definida por tres factores, protección contra los depredadores, es decir (condiciones de seguridad), confort contra las inclemencias del tiempo y centro de información, para proporcionar un punto de vista destacado en relación con el entorno inmediato (Almeida, C; Mora, J.; Dosreis, F.; 2010).

En tanto el determinismo geográfico el lugar y el clima, ni los materiales son los que determinan el modo de vida o el hábitat humano. Las viviendas y aglomeraciones no son el resultado único de las fuerzas fisioclimáticas (Almeida, C; Mora, J.; Dosreis, F.; 2010), sobre todo, donde las formas arquitectónicas cambian en las zonas donde la geografía no ha cambiado. Lo que decide en última instancia sobre la forma de una vivienda y modela 
sus espacios y su organización, es la visión que un pueblo tiene de lo que es la forma de vida ideal, que se irá reflejando en las diferentes interpretaciones de la idea de hogar y territorio (Rapoport, 2002).

En el Perú el $46 \%$ de la población peruana tiene por lo menos una necesidad básica insatisfecha, el 28\% carece de servicios higiénicos y el 24\% vive en condiciones de hacinamiento (Minsa, 2014). Esta situación conllevó a involucrar personas, familias y comunidades en un proceso de cambio orientado a modificar las condicionantes y determinantes de la salud, habiéndose elaborado programas de promoción de la salud, entre los que se encuentra el de familias y viviendas saludables que se especifica la Resolución Ministerial No 402-2006/Minsa.

Una organización adecuada de las viviendas en relación a su entorno geográfico genera condiciones para una vida digna de las familias y oportunidades de desarrollo personal de niñas y niños. El lugar y entorno familiar es influyente para no desperdiciar el talento o de los que pudieron ser y no fueron, sin embargo, muchos no tendrán el lugar ni entorno familiar adecuado, pero sí una vivienda organizada que puede marcar una influencia de lograr las metas y desarrollo personal (Martínez, 2015)

Mediante el aporte de los estudios multidisciplinarios se llega a comprender la lógica de la vivienda rural, donde se desarrollan una serie de actividades vinculados a la agricultura; las relaciones familiares internas y externas donde se forman las redes sociales de las comunidades; y la cultura que rige sus comportamientos familiares y sociales (Sánchez y Jiménez, 2010).

¿Existe el derecho a la vivienda adecuada? Si bien en la Constitución Política no se incorporó de manera expresa, pero se interpreta que se encuentra estrechamente ligado con el principio de dignidad humana. El contar con un ambiente adecuado, saludable, seguro y apropiado a las necesidades de la persona resulta indispensable para que ésta pueda desarrollar con el mayor grado de libertad todos los tributos inherentes a su persona (Acuerdo de concejo municipal de Paita, 2014)

La precariedad de la vivienda o la vulneración acarrea derechos compuestos, haciendo peligrar la integridad física y mental, que se encuentra en permanente preocupación, cuando se vive bajo la presión de un alquiler que no se puede pagar. Asimismo, dificulta el derecho a la educación, a la salud y al libre desarrollo de la personalidad y carentes de las condiciones mínimas de habitabilidad (Pisarello, 2016).

En países como el nuestro, donde las necesidades habitacionales son amplias y un gran sector de la población carece de las condiciones mínimas de calidad en su vivienda (viviendas jurídica y geográficamente inseguras, viviendas sin servicios básicos como agua, desagüe y electricidad, viviendas no adecuadas a las condiciones climáticas, o viviendas pequeñas e insalubres), la consideración de la vivienda digna como derecho fundamental debe suponer una priorización de esta necesidad básica en las políticas públicas estatales, sobre todo a favor de las sectores más vulnerables de la población (Tribunal Constitucional, 2010)

La Declaración Universal de los Derechos Humanos, en su artículo 25.1 indica "Toda persona tiene derecho a un nivel de vida adecuado que le asegure, así como a su 
familia, la salud y el bienestar, y en especial la alimentación, el vestido, la vivienda, la asistencia médica y los servicios sociales necesarios"

El Pacto Internacional de Derechos Económicos, Sociales y Culturales en su artículo 11 menciona "Los Estados partes en el presente pacto reconocen el derecho de toda persona a un nivel de vida adecuado para sí y su familia, incluso alimentación, vestido y vivienda adecuados, y a una mejora continua de las condiciones de existencia"

En las zonas rurales las familias a través de los años establecieron sus pautas de vida inmersos en la precariedad, estas viviendas son autogestionada, auto promovida, autoadministrada y autoconstruida (Vargas, 2000)

Mediante Decreto Supremo No 001-2012-VIVIENDA de fecha 7 de enero del 2012, se crea el Programa de Apoyo al Hábitat Rural (PAHR) con el propósito de mejorar la calidad de vida de la población pobre y extremadamente pobre asentada en los centros poblados rurales o asentada de manera dispersa, a través de acciones de dotación o mejoramiento de la unidad habitacional. Asimismo, generar igualdad de oportunidades y desarrollar y fortalecer sus capacidades individuales y comunitarias.

Actualmente el Programa Nacional de Vivienda Rural construye unidades habitacionales cuya característica principal es ser "confortables y seguras, brindan confort térmico especialmente en zonas con presencia de heladas y proporcionan seguridad estructural".

La vivienda es el espacio que se habita, se debe comprender en forma interna y externa, porque allí se producen las actividades diarias del hombre (mujer y varón). Este espacio debe estar implementado con servicios básicos que garanticen el bienestar del hombre, tanto las necesidades físicas, intelectuales, emocionales y espirituales (Mellado, 1986).

\section{METODOLOGÍA}

Se tomó en cuenta la metodología del Cambio Más Significativo propuesta por el Consorcio de la Comunicación para el Cambio Social (2015), que comprende 4 pasos:
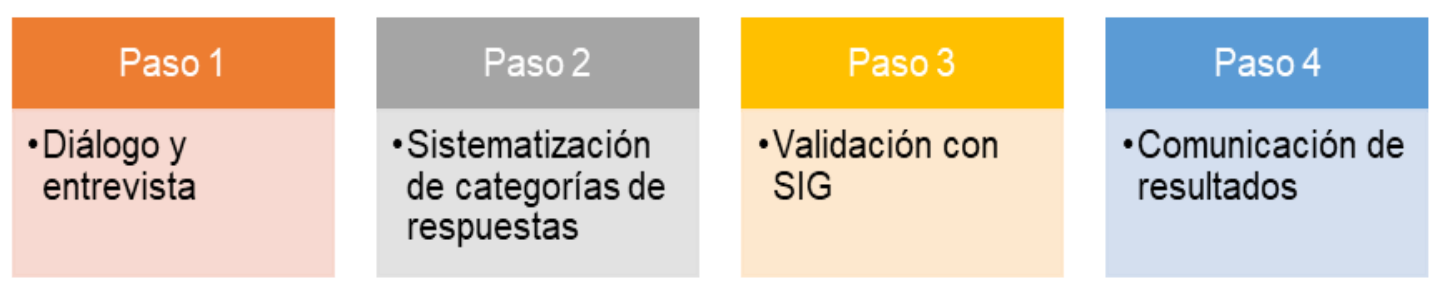

Para el paso 1, se identificó actores claves conformado por mujeres y varones y se dio inicio de manera individual el diálogo y entrevistas; en el paso 2 se sistematizó en categorías de respuesta (ver gráfico 2) a partir del diálogo y entrevistas seleccionando las palabras que se repitieron más de una vez, en el paso 3, las respuestas obtenidas en categorías de respuesta se validó con sistemas de información geográfica (SIG), cuyo proceso del análisis espacial de las viviendas siguió las fases que se muestra en el gráfico 1. 


\section{Gráfico 1}

Fases del análisis espacial territorial

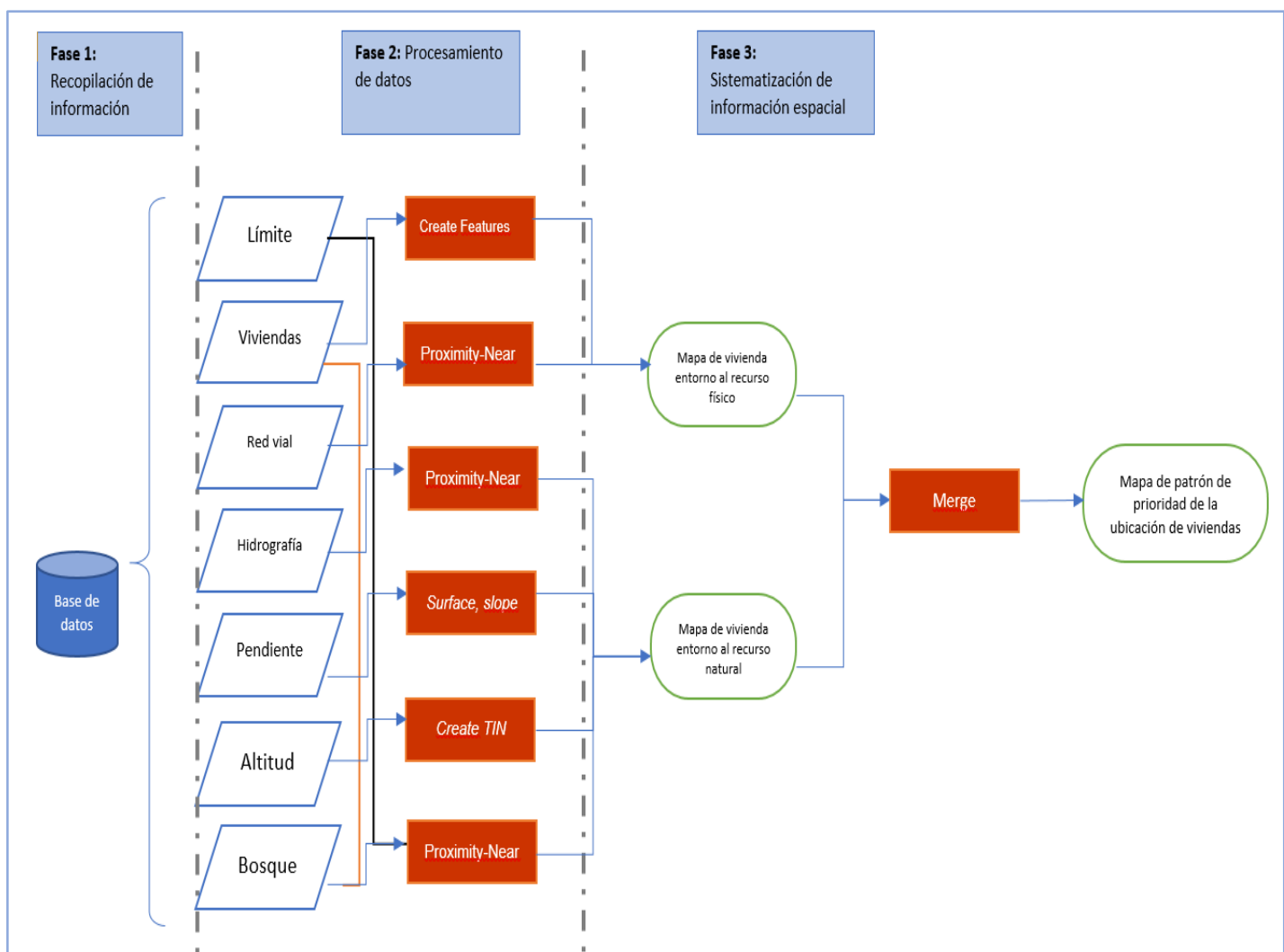

Fuente. Elaboración propia

Al culminar la validación con el SIG, en el paso 4 se elaboró la comunicación de la información con los resultados obtenidos.

La unidad de análisis se enfocó en el entorno geográfico rural del Centro Poblado de San Carlos de Juscaymarca, provincia de Cangallo, distrito de Los Morochucos en el departamento de Ayacucho - Perú.

\section{RESULTADOS Y DISCUSIÓN}

Los resultados se centran en el logro del objetivo de analizar la organización de las viviendas en un ámbito geográfico rural del centro poblado de San Carlos de Juscaymarca, ubicado en el distrito de Los Morochucos, provincia de Cangallo, departamento de Ayacucho, a una altitud de $3350 \mathrm{~m}$ s.n.m. Ver mapa 1.

Limita por el norte con la comunidad de Satica y Cuchucancha; por el sur con el centro poblado de Huallchancca y el distrito de María Parado de Bellido, por el oeste con el distrito de María Parado de Bellido y por el este con Pampa Cangallo, capital del distrito de Los Morochucos y la comunidad de Cuchucancha. 


\section{Mapa 1}

Ubicación del centro poblado de San Carlos de Juscaymarca

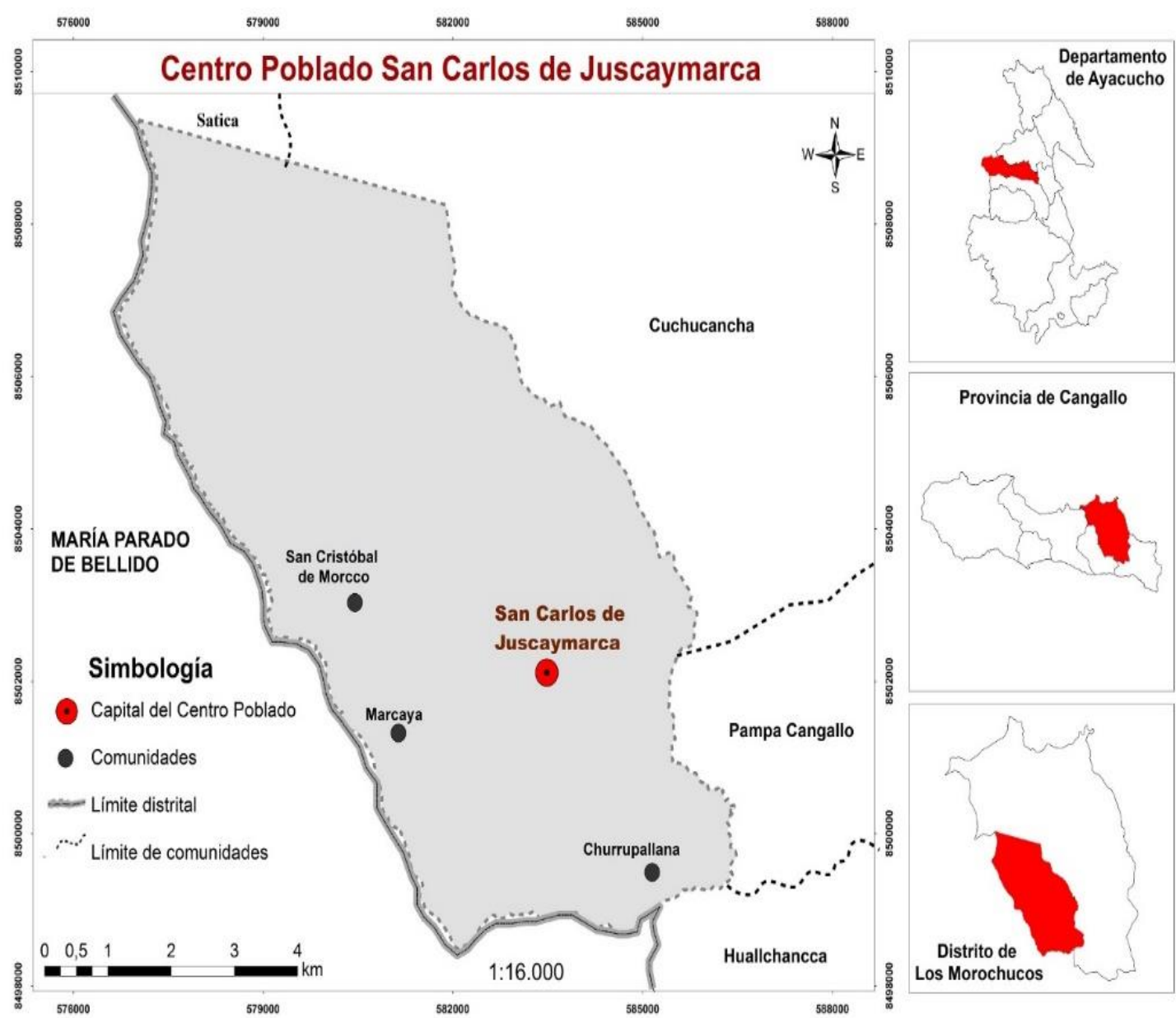

Fuente: Elaboración propia con datos de testamento y visita de campo.

a. Viviendas identificadas

Uno de los aspectos importantes en el estudio de la organización de la vivienda rural y en particular en los andes del Perú en el Centro Poblado San Carlos de Juscaymarca, es tener la capacidad de comprender y entender la situación que pasa en su interior, así como al exterior de la misma. Por tanto, en este estudio no sólo es relevante conocer el ¿por qué se construyó la vivienda en dicho lugar? también cuál fue el contexto social, económico, político, geográfico, entre otros que determinaron la estructura y ubicación de la vivienda.

En el mapa 2 se muestra el territorio del centro poblado de San Carlos de Juscaymarca y la ubicación de las viviendas, este proceso de elaboración de mapa temático se realizó con la finalidad de visualizar la organización de la vivienda en el ámbito espacial del centro poblado. 


\section{Mapa 2}

Ubicación de viviendas en el centro poblado de San Carlos de Juscaymarca

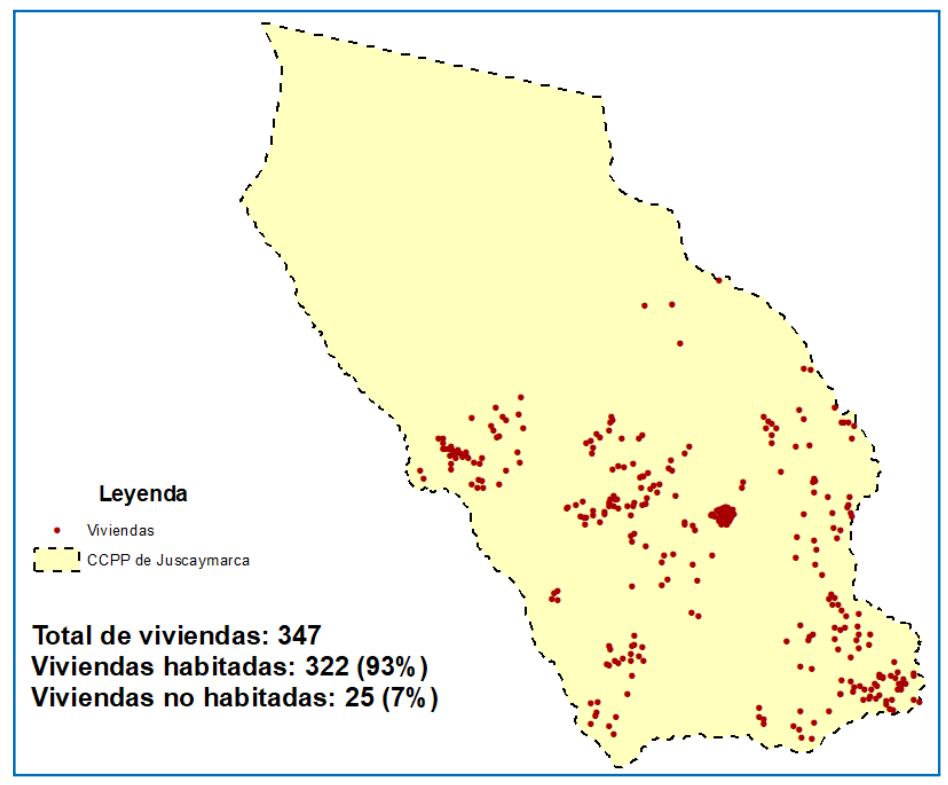

Fuente. Elaboración propia

Se identificó un total de 346 viviendas, de las cuales el 93\% (322) son habitadas y $7 \%$ (25) no habitadas. Una de las características notorias es la dispersión, como también

algunas conglomeraciones muy pequeñas. Es preciso mencionar justamente en estas conglomeraciones existen viviendas no habitadas que corresponden a las familias que emigraron con destino a diferentes lugares, en el siguiente testimonio se evidencia este proceso de migración sin retorno o en algunos casos con retorno temporal.

"Mi hermano vivia con su familia, pero hace 4 años se fue cerca de la ciudad de Pampa Cangallo y algunos de sus hijos a Lima, solo viene dos veces al año, pero un rato, ya no vive aquí su casa está abandonado. Yo vivo con mi esposa, mis hijos están en Lima, el día que ya no estemos nuestra casa se quedará abandonado, mis hijos no creo que regresen" (Vicente Calderón de 65 años)

El testimonio mencionado se repite, siendo la migración del campo a la ciudad una de las causas principales del abandono de las viviendas. Estas dinámicas sociales se evidencian como impacto favorable y desfavorablemente.

En el primer caso las hijas y los hijos que migraron logran oportunidades laborales en otras ciudades y optan enviar recursos económicos a sus familiares mejorando con ello su bienestar. En el segundo caso esta migración contribuye al decrecimiento poblacional y al aumento del adulto mayor. La migración de las últimas décadas está asociada al proceso de modernización y urbanización de la sociedad peruana. La gran atracción que poseen las nuevas áreas de colonización de la selva, aún para los residentes de las ciudades, es el cultivo y comercialización de las hojas de coca y su producto derivado como la droga (Matos, 1990)

\section{b. Selección del área para las viviendas}

En el proceso de entrevista y diálogo con los pobladores, el gráfico 2 muestra las prioridades que consideraron para escoger el lugar y construir la vivienda. En total de las 40 personas dialogadas y entrevistadas 27 de ellas mencionaron como primera opción 
haber tenido en cuenta para la construcción de sus viviendas la cercanía del lugar de a una fuente de agua.

\section{Gráfico 2}

Prioridades de selección de área para la ubicación de viviendas

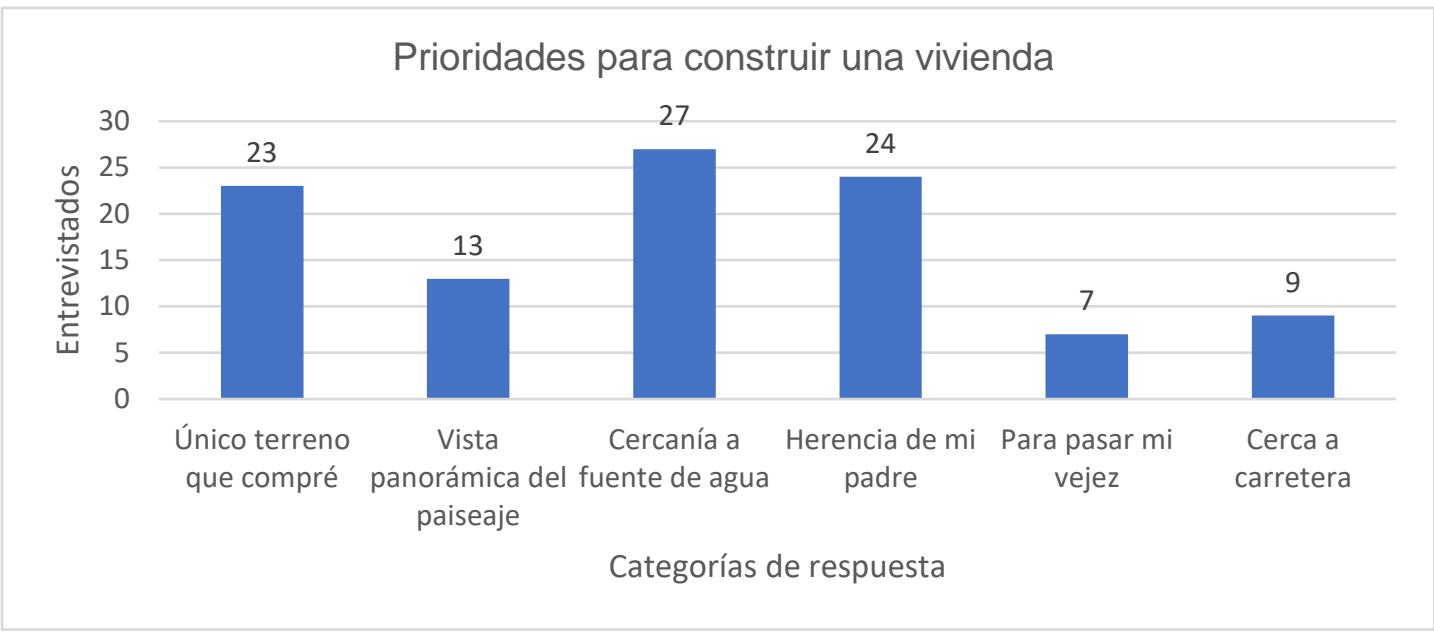

Fuente. Elaboración propia a partir de las entrevistas

Las otras prioridades que indicaron no significan que el tema de agua no fue considerado, más al contrario en su momento de construcción ya no era necesario, puesto que ya disponían de este recurso porque ya existía instalaciones de tubería y por ello tomaron otras prioridades como el acceso a vías de comunicación.

A partir de las prioridades y respondiendo la pregunta de ¿Cómo están organizado las viviendas familiares en un ámbito geográfico rural? se elaboró un mapa temático para contrastar las entrevistadas respecto a la ubicación de viviendas a una fuente de agua, ver mapa 3.

\section{Mapa 3}

Organización de viviendas en relación a los ríos

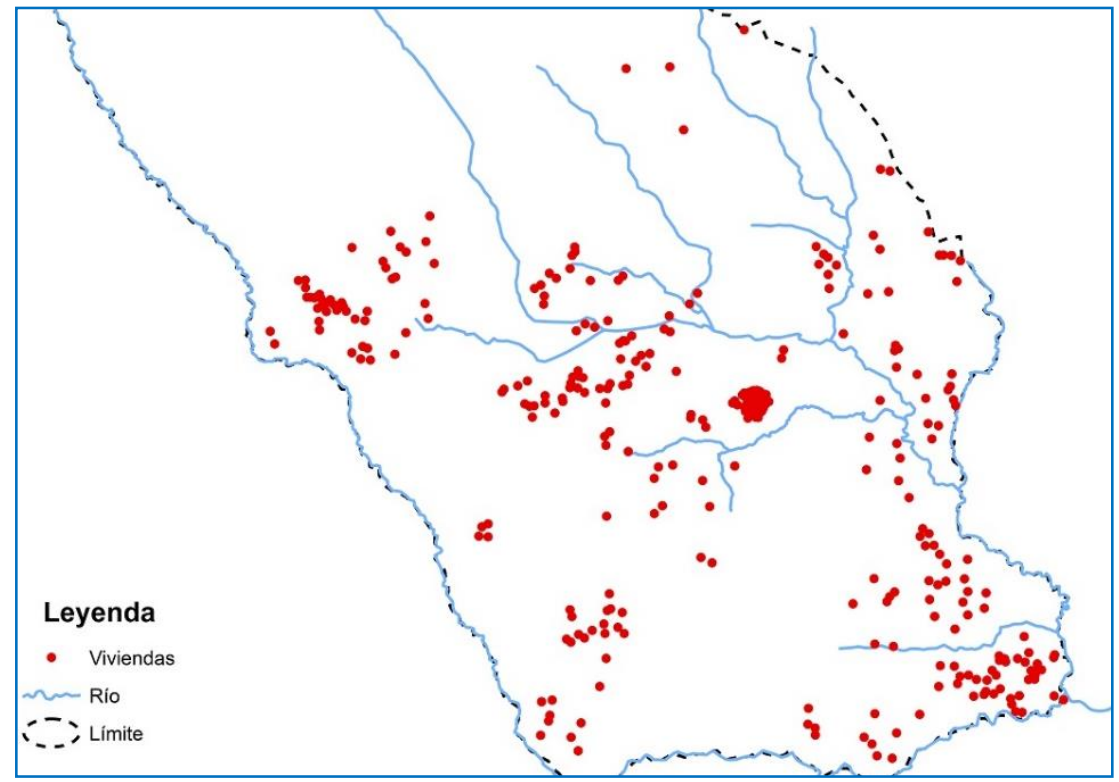

Fuente. Elaboración propia 
En el mapa 3 la configuración de un territorio con las viviendas desplegadas a nivel del curso de los ríos, evidencia la priorización del agua como un factor determinante para la construcción de las viviendas. Este resultado permite dar la explicación de ¿Cómo están ubicados las viviendas en relación a su entorno geográfico rural? A partir de las entrevistas y construyendo las categorías de respuesta, apoyado con el mapa temático se asevera que los pobladores tomaron como un criterio de construcción la cercanía al agua.

"Wak qatachapi, nawi yaku tuqyaqpa waqtalawnimpi ruwakuraniku wasita, mana karupi kanaykupa...” En la bajada donde está el ojo del agua, hemos construido nuestra casa para estar cerca a ella... (Jorge Roca de 66 años)

Pero también en algunos casos no fue condicionante, más al contrario lo que determinó en última instancia fue tener un terreno propio sin importar la cercanía al agua.

"A mi padre no le importó construir su casa en este lugar que estamos lejos de una fuente de agua, nosotros con mis hermanos íbamos todos los días con nuestro recipiente caminando como 20 minutos a traer agua..." (Faustino Cisneros de 79 años).

Otra de las categorías que también se toma en cuenta para escoger el lugar de construcción de una vivienda y en mayor parte por los jóvenes es la accesibilidad a vías de comunicación principalmente la carretera que une a la capital distrital.

“... a mi me gustaría construir mi casa cerca de la carretera para sacar mis productos con carro y vender en el mercado y también traer mi compra y bajar del carro en la puerta de mi casa..." (Rosa Roca de 38 años)

\section{c. Distancia de las viviendas a una fuente de agua}

La distancia de las viviendas en relación a los ríos se calculó para tener una aproximación de medida, en el mapa 4 se representó las viviendas en diverso s colores dependiendo la distancia a los ríos, el color rojo marca las viviendas más cercanas al río y el color verde las más lejanas, tal como se muestra en la simbología.

Los colores rojos representan las viviendas ubicadas muy cerca de los ríos entre 13 a $200 \mathrm{~m}$. En tanto el color verde son viviendas muy alejadas de los ríos entre 1000 a 1218 m. sin embargo estas viviendas muy alejadas de los ríos son construcciones de hace 15 años que tienen acceso al agua entubada. En el campo ecológico la ubicación de la vivienda es considerada como una necesidad de interrelación del hombre con su ambiente. Las formas y estilos de vivienda responden a un modo establecido de construcción, que no surgió con independencia del clima y de los paisajes locales. La casa es un recurso para protegerse del frío y del calor, así como para soportar las lluvias, los vientos, los incendios y terremotos (Almeida, C; Mora, J.; Dosreis, F.; 2010). Estos condicionamientos priorizan el ranking hasta llegar al estilo de vivienda propio de una región (Odum, 1997). 


\section{Mapa 4}

Distancia de las viviendas a una

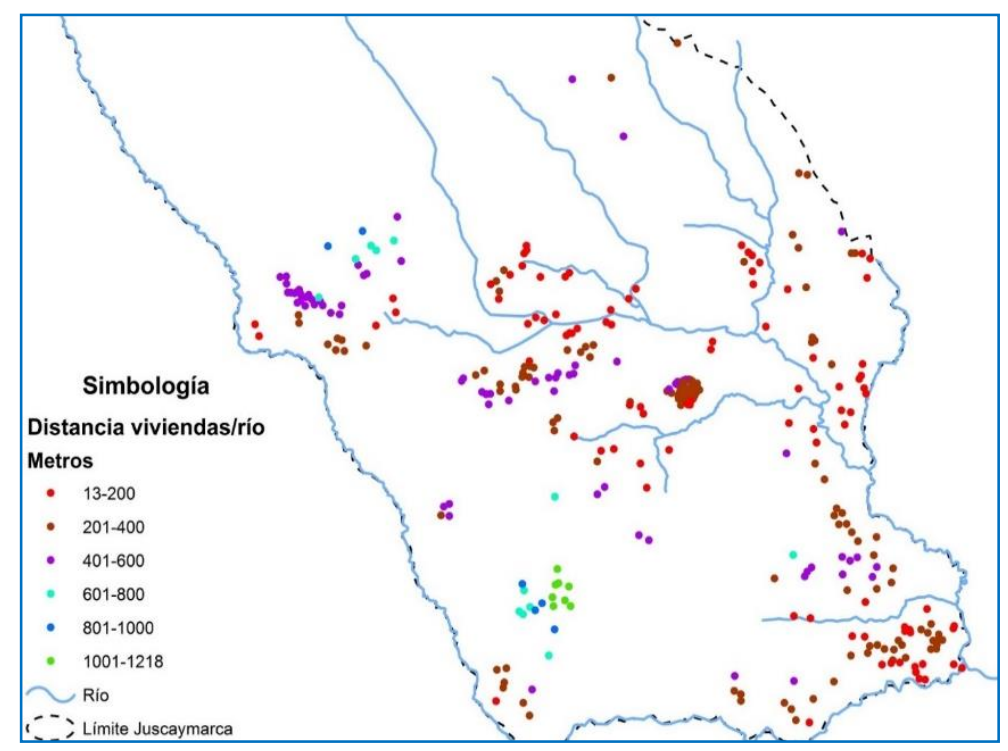

Fuente. Elaboración propia

En el gráfico 3 se muestra el número de viviendas y la distancia en metros. En total de las 347 viviendas registradas 93 de ellas están muy cerca a los ríos entre $13 \mathrm{~m}$ a $200 \mathrm{~m}$ de distancia y 8 viviendas muy lejos entre $1001 \mathrm{~m} 1218 \mathrm{~m}$.

\section{Gráfico 3}

Distancia de viviendas en relación a los ríos

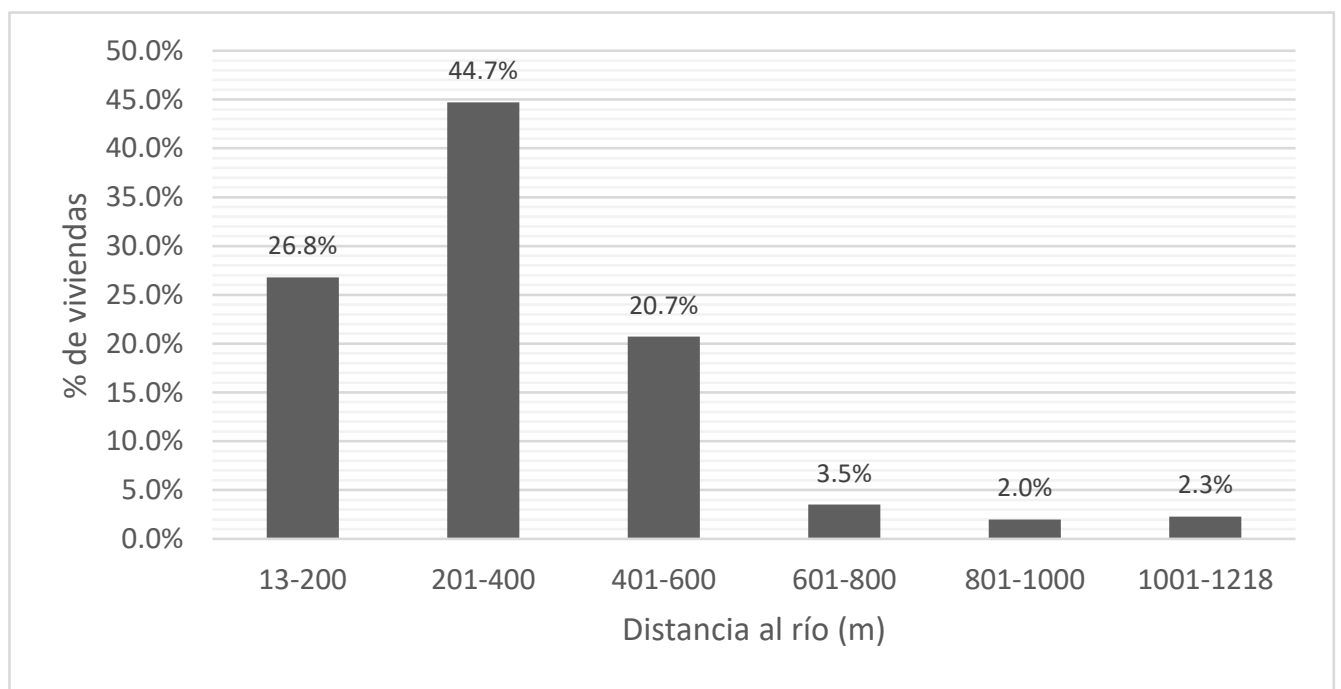

Fuente. Elaboración propia de trabajo de campo

En $44.7 \%$ de las viviendas se encuentran entre $201 \mathrm{~m}$ y $400 \mathrm{~m}$ de distancia hacia a los ríos, esto representa 155 viviendas, siendo el mayor número de viviendas ubicadas a esta distancia. Mientras tanto el $2.3 \%$ que son 8 viviendas se encuentran entre $1001 \mathrm{~m} \mathrm{a}$ $1218 \mathrm{~m}$, que son considerados las más lejanas, sin embargo, estas a pesar de la lejanía al río, tienen muy cerca a un promedio de 50 metros los puquiales o sequias, en su defecto agua entubada y potable. 


\section{d. Material de construcción de la vivienda}

El tipo de vivienda es muy similar en todo el territorio del Centro Poblado de San Carlos de Juscaymarca. El material de construcción utilizado en $95 \%$ de las viviendas es el adobe, el 4\% con roca y barro, mientras tanto menos del 1\% con material noble. Para el techo de las viviendas el $97 \%$ es calamina, seguido por el ichu - Stipa ichu (2\%), teja $(0.8 \%)$ y eternit $(0.20 \%)$, ver gráfico 4.

\section{Gráfico 4}

Material de construcción y techo de vivienda

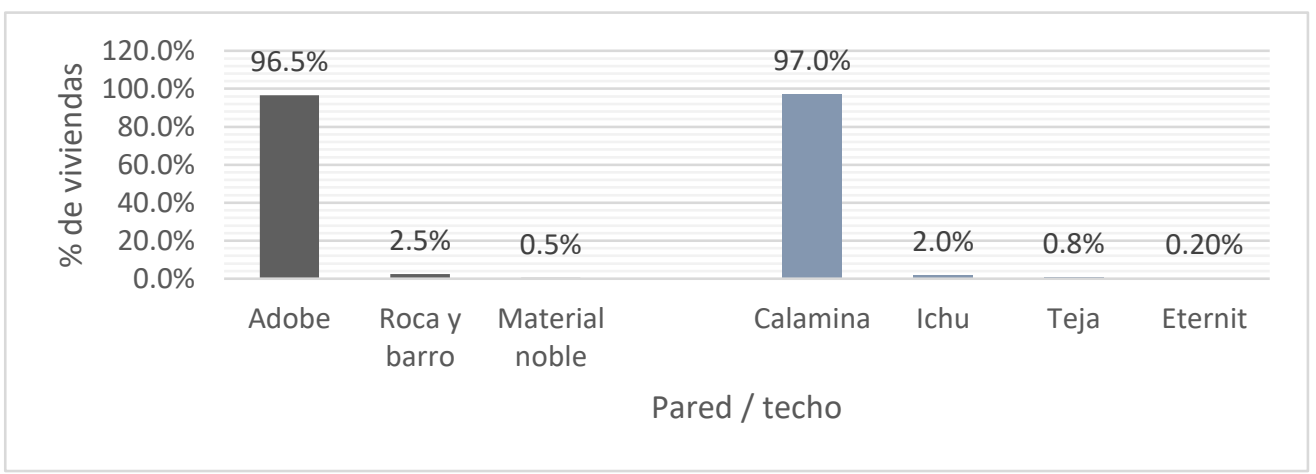

Fuente. Elaboración propia de datos de campo

La autoconstrucción permite detectar graves carencias y necesidades que son ignoradas como problemática de la vivienda rural. El acceso al suelo, a través de la herencia familiar, posibilita contar con un espacio habitacional para dar forma al proyecto de vida de formar una familia, sin embargo, en la mayoría de los casos, se materializan en un cuarto rectangular o cuadrado (Torres, 2011)

\section{e. Ambientes de la vivienda}

El número de ambientes por vivienda es un factor determinante para conocer la calidad de vida respecto al espacio con que cuenta la familia para su merecido descanso. Las habitaciones tienen pequeñas variaciones, presentando desde un mínimo de un dormitorio hasta un máximo de 7 dormitorios por vivienda. El $26 \%$ de viviendas tienen 3 habitaciones y el 6.6\% una sola habitación, ver gráfico 5 .

\section{Gráfico 5}

Número de ambientes

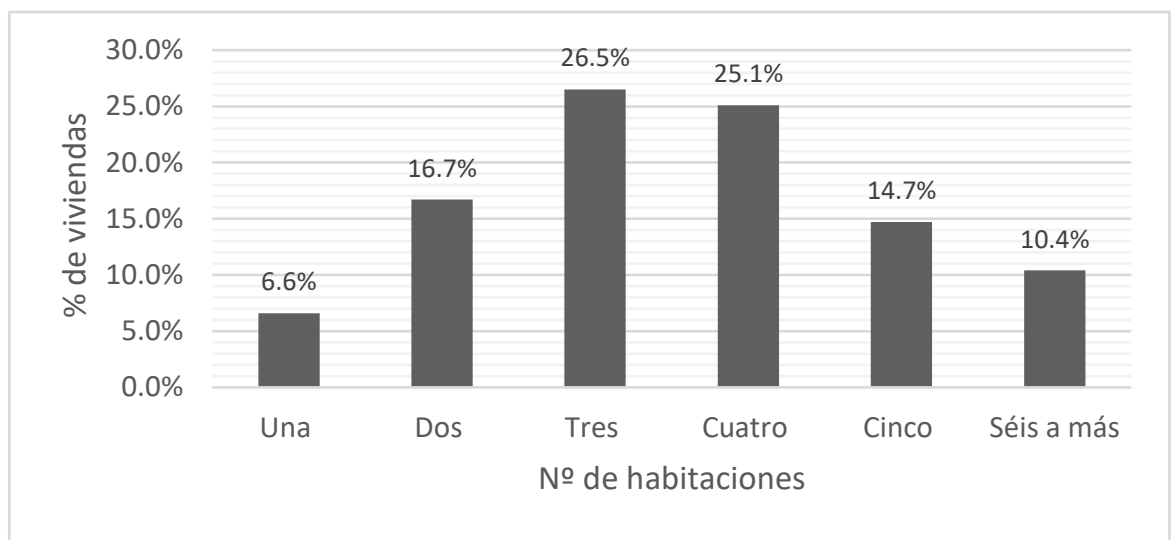

Fuente. Elaboración propia 
Es posible que la autoconstrucción conlleva a detectar graves carencias de servicios, puesto que son ignoradas la implementación que debe tener una vivienda planteada con enfoque de desarrollo humano, cultural, territorial, género e identidad (Martínez, 2014). El Estado en cumplimiento del derecho a la vida digna de las personas, debe garantizar el bienestar a la población, el Perú no logra satisfacer el derecho a la vivienda, teniendo implicancias en la salud de las familias.

En Austria se encontró más afectación en la salud de los niños que vivían en multifamiliares rurales que los de casas independientes (Evans, Saltzman \& Cooperman, 2001). En las zonas rurales las casas son independientes, sin embargo, posee limitaciones en el modo de ocupar los espacios.

Las formas de organización de las viviendas son indicadores de calidad de vida y sus elementos físicos tienen un impacto importante sobre la salud mental de los residentes, Pereira, Contreras, Guatarasma \& Mejía, 2001; Pérez, 2001. Una pobre calidad de vivienda observada por los indicadores: estructura, privacidad, clima interior, riesgos, higiene y recursos, pueden afectar el desarrollo mental de las personas (Evans, Lercher \& Kofler, 2002).

\section{f. Habitantes en la vivienda}

En el análisis del número de habitantes se encontró que el 36\% de viviendas tienen tres habitantes, generalmente padre madre y un hijo; un alto porcentaje de viviendas que tienen como dos habitantes es de $25 \%$, sobre todo en estas viviendas están madre y padre, puesto que los hijos ya salieron a diversos partes del Perú por factores laborales, académicos entre otros, gráfico 6.

\section{Gráfico 6}

\section{Número de habitantes de la vivienda}

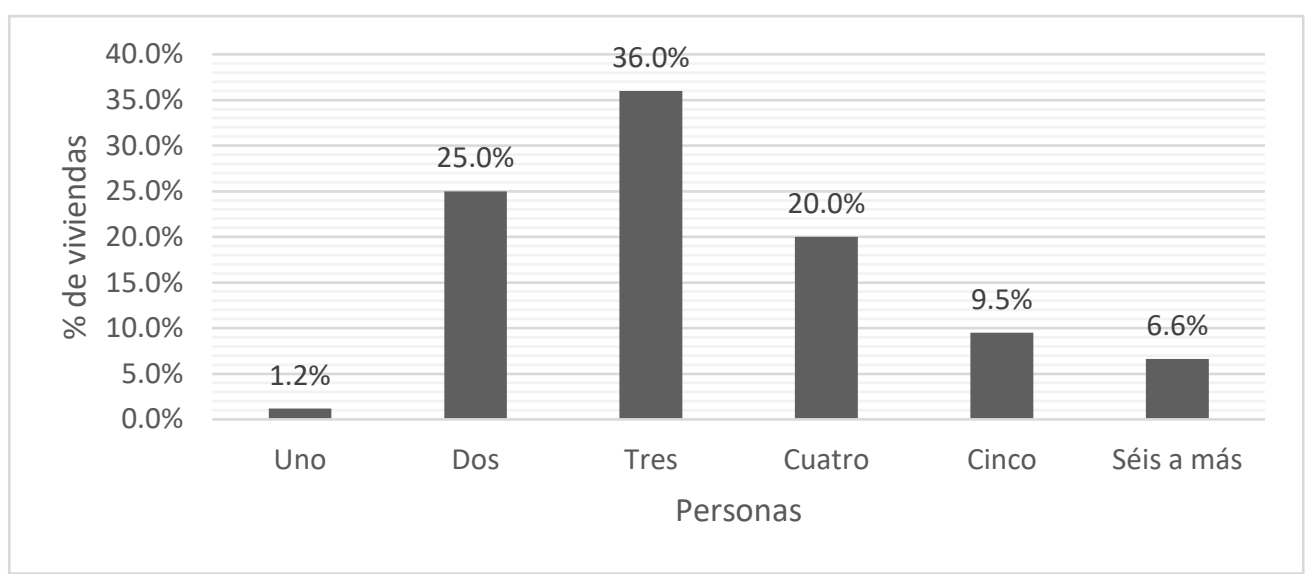

Fuente. Elaboración propia

En el análisis del gráfico 7 el 9.5\% de viviendas alberga 5 personas de las cuales utilizan el dormitorio de $20 \mathrm{~m} 2$ más de 4 personas, viendo las sugerencias del INEI (2018) esta situación conlleva que estas familias viven en hacinamiento.

Esta forma de ocupar el espacio no es muy adecuada y se genera el hacinamiento, conlleva a consecuencias negativas en la salud mental...Una cierta privacidad es un bien necesario, para los grupos de pares (padre-madre e hijos entre sî), y la separación de sexos, 
para la realización de determinadas actividades familiares como dormir, estudiar, estar, entre otras actividades (Lentini, 1997)

Especialmente las niñas y niños, son los más afectados por las carencias de espacio en sus necesidades de crecimiento y desarrollo, existen estudios que demostraron como efecto del hacinamiento el bajo rendimiento escolar y en algunos casos embarazo adolescente y tocamientos indebidos de tíos, primos, entre otros que ocupan el espacio (Suarez, D. 2014).

\section{g. Uso de los ambientes de la vivienda}

En la distribución de la vivienda familiar se organiza a partir de dos espacios, la cocina y el dormitorio. El primero destinado a actividades domésticas, en ella se desarrolla la convivencia familiar, mientras tanto el segundo es el espacio de pasar la noche.

En las cocinas independiente entendido esta como un ambiente netamente para la cocina el $90.6 \%$ de las familias lo tienen, mientras tanto el $9.4 \%$ poseen cocina como dormitorio, es decir lo usan un ambiente para dormir y cocinar sus alimentos. Ver gráfico 7.

\section{Gráfico 7}

Cocinas segín categoría de uso

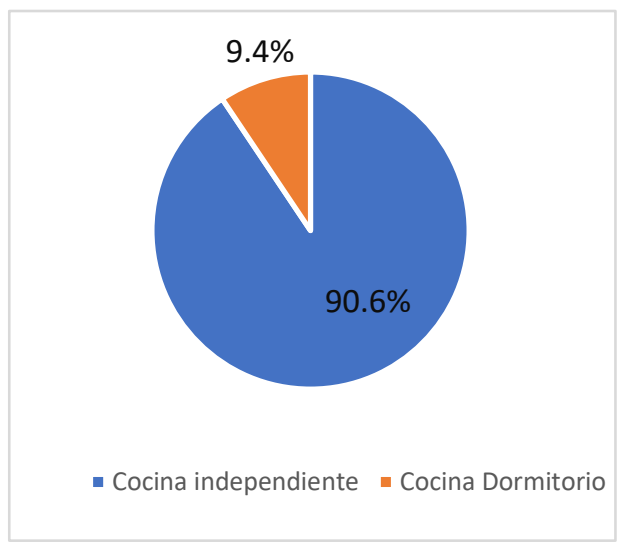

Fuente. Elaboración propia

"Puñuchakuni yanukunay wasipin, qunichallaña katin, piñama huqtapas ruwanqa, kaniku mana kallpayuqñam" Duermo en la cocina, porque es caliento, además ya no bay fuerza para construir" (Testimonio de una pobladora)

El $9.4 \%$ de las familias tienen cocina multi uso, como dormitorio, almacén...asimismo $80 \%$ de las cocinas es un ambiente cerrado, 95\% de las familias utilizan la leña para preparar sus alimentos, el humo emitido por uso de leña es perjudicial para la salud, puesto que contienen el monóxido de carbono, partículas, benceno, 1-3 butadien y formaldehido, entre otros. En tres comunidades altoandinas, los niveles de exposición a las sustancias tóxicas en la combustión de la biomasa supera 10 a 20 veces el límite recomendado por la OMS, siendo las mujeres, niñas y niños menores de 14 años los más expuestos y vulnerables, pues son los que pasan mayor tiempo del día en la cocina (Accinelli, 2004).

Estas cocinas tradicionales no cuentan con lavaderos y si en caso existe las personas están expuestas durante el proceso de fregar los servicios al agua fría, según Francke 
(2007) las enfermedades que aquejan a los ancianos en los andes del Perú es reumatismo y artritis por exposición al agua fría. Más aun en los meses de junio a agosto que desciende hasta $-4^{\circ}$

\section{CONCLUSIONES}

- Las viviendas en el ámbito rural están dispersas por condiciones que necesariamente no obedecen las cadenas productivas o actividades económicas, si no por elementos del entorno geográfico siendo primordial la cercanía al agua, el $44.7 \%$ de viviendas se ubican entre 200 a $400 \mathrm{~m}$ de distancia a una fuente de agua como el río para el abastecimiento de este elemento en menor tiempo posible y utilizar en la preparación de alimentos, higiene y consumo de sus animales.

- Los aspectos comunes fueron la existencia en promedio de tres ambientes por vivienda, el techo de calamina, las paredes de adobe, el corral de animales muy cerca a los dormitorios, habitaciones multiusos donde a la vez funciona como cocina, dormitorio, almacén de productos y herramientas de trabajo.

- La forma actual de organización de las viviendas, si bien garantiza la habitabilidad (se ocupa, pero no se vive bien), sin embargo, no el uso adecuado de los ambientes que son precarias con implementación carente de materiales y muebles para el pleno desarrollo psicomotriz, salud mental y emocional; principalmente que afecta a niñas, niños, adolescentes y adultos mayores.

\section{REFERENCIAS BIBLIOGRÁFICAS}

Accinelli, R; Yshii, C.; Córdova, E.; Sánchez, S. (2004) Efectos de los combustibles de biomasas en el aparato respiratorio: impacto del cambio a cocinas con diseño mejorado

Acuerdo de concejo Nº 048-2014-CPP de la municipalidad provincial de Paita (2014)

Almeida, C.; Mora, J.; y Reis, D. (2011). Vivienda y Territorio. Lisboa

Consorcio de Comunicación para el Cambio Social. Recuperado de http://archive.cfsc.org/pdf/cfsc_consortium_brochure_spanish.pdf

Evans, G. W., Saegert, S. y Harris, R. (2001). Residential density and psychological health among children in low-income families. Environment and Behavior, 33(2), 165-180.

Francke, M. y Reynoso, R. (2007). Salud y enfermedad en los márgenes: Diagnóstico participativo en comunidades peruanas que sufren pobreza y exclusión. Lima.

González, C. (2001). Vivienda rural en México. Vivienda rural y calidad de vida en los asentamientos rurales. Santiago de Cuba: Cyted-Habyted.

INEI (2018). Perú: Enfermedades No Transmisibles y Transmisibles.

INEI (2016). Demografía en el Perú. Lima

Jiménez, R.; Eric, O. y Verduzco C. (2009). La sintaxis espacial de la vida doméstica. Una comparación urbano-rural. México. 
Lentini, M. y Delta, P. (1997). El Hacinamiento: La dimensión no visible del déficit habitacional. Chile. Recuperado http://revistainvi.uchile.cl/index.php/INVI/ article/view/220/195

Matos, J. (1990). Las migraciones campesinas y el proceso de urbanización en el Perú. Recuperado de https://centroderecursos.cultura.pe/sites/default/files/rb/pdf/ Las $\% 20$ migraciones $\% 20$ campesinas $\% 20 \mathrm{y} \% 20 \mathrm{el} \% 20$ proceso $\% 20 \mathrm{de} \% 20$ urbanizaci on $\% 20$ en $\% 20$ el $\% 20$ Peru $\% 20$ Matos $\% 20$ Mar.pdf

Ministerio de Salud (MINSA), 2014. Familias y Viviendas Saludables. Lima. Pág. 19. Recuperado http://bvs.minsa.gob.pe/local/PROMOCIÓN/151_progfam.pdf

Martínez, J. (2015). Las grandes oportunidades del mundo que viene.

Naganoma, C. (2013). Proocesos de formación y transformación de comunidades campesinas. Los casos de las comunicades de San Antonio de Cuchucancha y Chalco, Ayacucho. Recuperado de https://es.scribd.com/document/ 373887899/3-Procesos-de-Formacion-y-Transformacion

Organización Mundial de la salud. (2018). Contaminación del aire de interiores y salud. Recuperado de https://www.who.int/es/news-room/fact-sheets/detail/ household-air-pollution-and-health

Odum, E. (1997): Fundamentos de Ecología. Fundación Calouste Gulbenkian. Lisboa, p.375.

Pisarello, G. (2003) Vivienda para todos: derecho en construcción Barcelona. Recuperado de https://archivos.juridicas.unam.mx/www/bjv/libros/10/4556/12.pdf

Plan Nacional de Vivienda 2006 - 2015 (2006) "vivienda para todos" - Ministerio de vivienda. Lima. Recuperado http://www3.vivienda.gob.pe/transparencia/ documentos/varios/pnv.pdf

Pereira, N., Contreras, W., Guatarasma, L. y Mejía, N. (2001). En J. González (Ed.), Memorias del 3er Seminario sobre Vivienda rural y calidad de vida en los asentamientos rurales, (pp. 263-274).

Rapoport, A. (2002). House Form and Culture. Prentice Hall Foundations of Cultural Geography Series, Ed. Philip L. Wagner. New York.

Resolución Ministerial No 402-2006-DGPS-MINSA. Programa de familias y viviendas saludables.

Suarez, D. (2009). Ayacucho: Análisis de situación en población. Recuperado de http://www.unfpa.org.pe/publicaciones/publicacionesperu/UNFPA-CIES-ASPAyacucho.pdf

Sánchez, C., Jiménez, Eric. (2010). La vivienda rural. Su complejidad y estudio desde diversas disciplinas. México.

Torres, E., Vega, L., y Higuera, C. (2011). La dimensión socio espacial de la vivienda rural en la ciudad de México. El caso de la Delegación Milpa Alta. Revista INVI, 26(73), 201-223 
Tribunal Constitucional. (2010). Sentencia Nº0011-2010-PI/TC. Perú

Vargas, L. (2000). Vivienda rural y calidad de vida en México. En J. González y M. Villar, (Eds.), II Seminario y taller iberoamericano sobre Vivienda rural y calidad de vida en los asentamientos rurales. (Vol. I, pp. 49-66). México: Universidad Autónoma de San Luis Potosí.

CITAR COMO:

Aronés Cisneros, A. A. (2021). Organización de las viviendas en un entorno geográfico rural. Puriq, 3(1), 120-135. https://doi.org/10.37073/puriq.3.1.92 